\title{
Congreso Nacional de Farmacia
}

A Facultad de Ciencias de la Universidad de Concepción y la Sociedad Farmacéutica han tomado la iniciativa de organizar un Congreso Nacional de Farmacia que ha de celebrarse en nuestra ciudad el 17 de Septiembre de este año. para concurrir a la inauguración del nuevo local de la Escuela de Farmacia y Quimica de nuestra Universidad.

Tiene por objelo este primer Congreso Chileno de Farmacia propender al perfeccionamiento y dignificación profesional de la carrera respectiva y al desarrollo intensivo de la ciencia farmacéutica: se estudiarán en él todas las cuestiones relacionadas con el levantamiento del nivel social del farmacéutico. con su posición ante la nueva legislación sanitaria, con la reforma de los programas de estudios, con la formación de una gran Asociación Farmacéulica de Chile. etc.. etc.

Las diversas malerias que constituyen el programa del Congreso se han agrupado en dos secciones generales:

A) Instrucción y legislación, y

B) Temas referentes a la profesión misma.

Junto con celebrarse las sesiones del Congreso. se abrirá en el local de la Escuela de Farmacia una gran Exposición de productos famacéuticos, cuyo éxito es seguro, si se considera la notable acogida que esta idea ha encontrado entre los interesados.

La Comisión organizadora del Congreso está constifuida en la siguiente forma: Presidente: don Salvador Gálvez R.. Tesorero: don Evans Weassor, Vocales: Dr. don Guillermo Grant B.. don Alejandro Paredes, don Enrique Giraud, don Juan. Ze- 
melman, don Luis Mayorga, don Augusto Pfister y doña Elisa Guerra, Secretarios Generales: don J. Ernesto Mahuzier y don Juan Perelló P.

Los siguientes son los temas oficiales del Congreso:

I.-Legislación farmacéulica.

II.-Reforma del plan de estudios de la Escuela de Farmacia.

III.-Farmacopea nacional.

IV.-Asociación Farmacéutica de Chile.

V.-Etica profesional.

VI.-Creación de la Facultad de Farmacia.

VII.-Protección a la Industria farmacéutica nacional; Arancel aduanero y Ley de impuestos a los especificos.

Todos los dafos relativos al Congreso deben solicilarse a la Secrefaria de la Comisión organizadora (Concepción. O'Higgins 850, Casilla 265). 